\title{
Cathodoluminescent Features and Raman Spectroscopy of Miocene Hydrothermal Bio- mineralization Embedded in Cryptocrystalline Silica Varieties, Central Europe, Hungary
}

\author{
A. Müller ${ }^{\mathrm{a}}$, M. Polgári ${ }^{\mathrm{b}}$, A. Gucsik , E. Pál-Molnár ${ }^{\mathrm{a}}$, M. Koós ${ }^{\mathrm{d}}, \mathrm{M}$. Veres ${ }^{\mathrm{d}}$, \\ J. Götze ${ }^{\mathrm{e}}, \mathrm{Sz}$. Nagy ${ }^{\mathrm{f}}, \mathrm{Cs}$. Cserháti ${ }^{\mathrm{g}}, \mathrm{T}$. Németh ${ }^{\mathrm{b}}, \mathrm{M}$. Hámor-Vidóh \\ ${ }^{a}$ Szeged University, Dept. of Mineralogy, Geochemistry and Petrology, 6702 Szeged, Egyetem str. 2-6, \\ Hungary \\ ${ }^{b}$ Institute for Geochemical Research, 1112 Budapest Budaörsi str. 45, Hungary \\ ${ }^{c}$ Max Planck Institute for Chemistry, Dept. of Geochemistry, Joh.- J. Becherweg 27, D-55128, Mainz, \\ Germany \\ ${ }^{d}$ Research Institute for Solid State Physics and Optics, H-1121 Budapest, Konkoly-Thege M. str. 29-33, \\ Hungary \\ ${ }^{e}$ TU Bergakademie, Freiberg, Department of Mineralogy, Germany \\ ${ }^{f}$ Eötvös University, Faculty of Science, Institute of Physics, Dept. Material Physics, H-1117 Budapest, \\ Pázmány Péter sétány 1/a, Hungary \\ ${ }^{e}$ Research Institute for Technical Physics and Material Sciences, H-1121 Budapest, Konkoly-Thege M. \\ str. 29-33, Hungary \\ ${ }^{g}$ University of Debrecen, Faculty of Science and Technology, Dept. of Solid State Physics, Debrecen, \\ Bem tér 18, Hungary \\ ${ }^{h}$ Eötvös Lorand Geophysical Institue, 1145 Budapest, Kolumbusz str. 17-23, Hungary
}

\begin{abstract}
Variable cryptocrystalline silica varieties occur en masse in the fractures and cavities of the andesite host rock, showing different genetic and morphological features of variable microbial activity. Four types of CL features characterized silica phases. Raman spectroscopy supported variable amorphous carbon phases in inhomogenous distribution.
\end{abstract}

Keywords: Biomineralization, cathodoluminescence, Raman spectroscopy, hydrothermal, Miocene

PACS: $78.60 . \mathrm{Hk}, 91.65 .-\mathrm{n}$, 91.67.Ty

\section{INTRODUCTION}

At the southern part of the Mátra Mts. (Hungary), in the neighborhood of Gyöngyöstarján and Gyöngyösoroszi area (Fig. 1), variable cryptocrystalline silica varieties occur en masse in the fractures and cavities of the andesite host rock near the surface [1]. The great variety of colour and morphology is caused by the different genetic and morphological features of variable microbial (bacterial and microcolonial fungi type) activity and interaction with inorganic hydrothermal vent system, which have embedded in cryptocrystalline silica matrix. The aim of this research is the characterisation of cathodoluminescent features of biomineralization products 
occurring in the samples, and the determination of the form of 1-3 wt. \% carbon content, giving further evidences of microbial contribution.
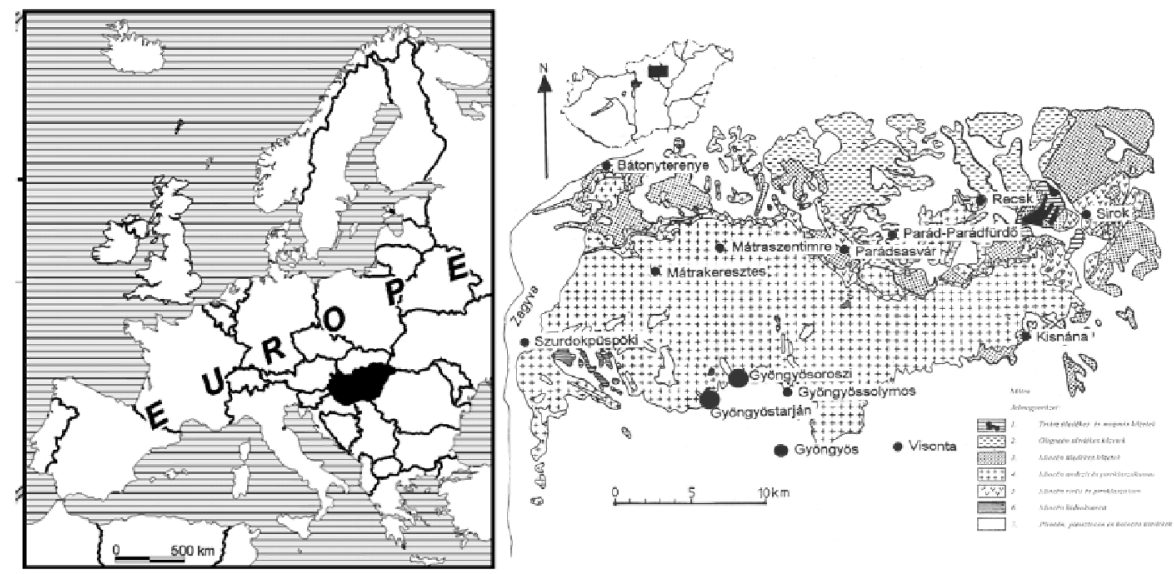

FIGURE 1. Southern part of the Mátra Mts., Gyöngyöstarján and Gyöngyösoroszi (big black solid circles) area in Central Europe.

\section{SAMPLES AND METHODS}

150 polished surfaces and 83 thin sections were investigated by rock and optical microscopy (reflected and transmitted, Nikon Eclipse 600 microscope), and selected samples by cathodoluminescence (Reliotron cold cathod, and hot-cathode" CL microscope $\mathrm{HC1}-\mathrm{LM}$, Acton Research SP-2356 digital triple-grating spectrograph with a Princeton Spec-10 400/B/XP CCD detector), fluorescence (Leica DM-RX research microscope), methods. X-ray powder diffraction measurements were carried out on 10 selected samples for determination of mineralogical composition (Philips PW 1710). Electron-microprobe analyses were made to determine element distribution and textural features on 8 thin sections (Nikon Eclipse 600 Hitachi S4300-CFE SEM with Bruker Quantax, XFlash 4010 detector). Additionally, the structural properties of the selected minerals were determined by a Renishaw-1000 Raman spectrometer, the laser wavelenght was $785 \mathrm{~nm}$, with focused energy of $8 \mathrm{~mW}$. The maximal focus was driven to $1 \mu \mathrm{m}$ spot in diameter. The thin sections were mounted in epoxy material, and the sample thickness is $30 \mu \mathrm{m}$. 


\section{RESULTS}

\section{Textural Features}

Detailed determination and description of textural features of the samples showed signs of complex microbial and inorganic interactions. The microbially mediated way of explanation for the studied Miocene hydrothermal vent formation was raised and proved for the first time. The signs of microbial activity are supported by the weathering formation of the host andesite, the variable and numerous rock varnishes on their surface, microbial forms (filamentous, coccoid and microcolonial fungi type, Fig. 2), and the textural features of the silica matrix, which genetic processes were modelling. The small and uniform grain size (phase dimension), the chemically poor occurrence also support the biogenic origin as well as the often occurring curved morphology and variable „large formats” built up from the same small units.
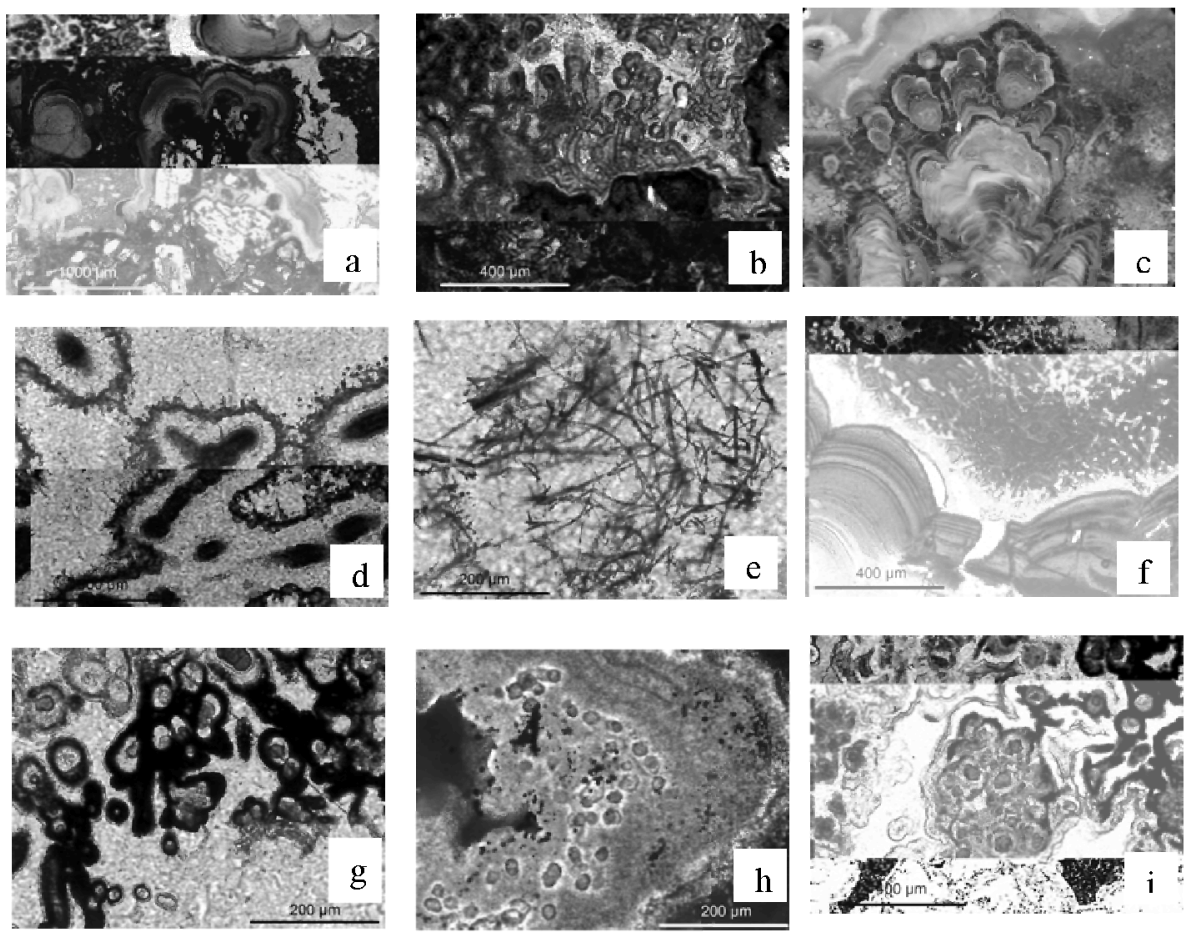

FIGURE 2. The signs of microbial activity in the host andesite, rock varnishes on their surface (a, b), stromatolites (c), microbial forms (filamentous ( $\mathrm{d}, \mathrm{e}, \mathrm{f})$, coccoid $(\mathrm{g}, \mathrm{h})$ and microcolonial fungi type forms (i). 


\section{Fluorescence Study}

The fluorescence study showed the remnants of organic matter in the samples occurring by greenish yellow colour indicated by a white circla in the Figure 3.
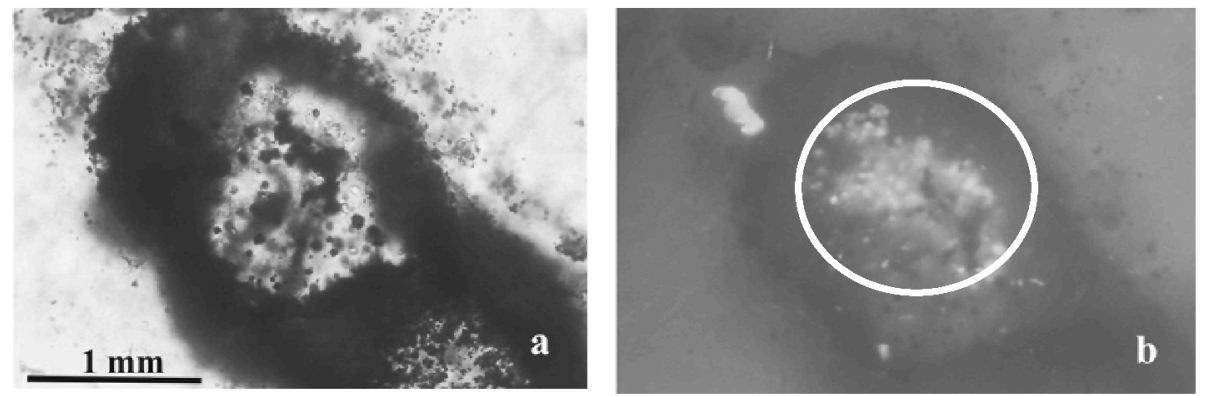

FIGURE 3. Thin section ( $a, 1 \mathrm{~N})$ and fluorescence photo (b) of biomineralization products.

\section{Electron Microprobe Analyses}

The electron-microprobe analyses determined 1-3 wt. \% $\mathrm{C}$ content in the silica matrix and in mineralized forms (Fig. 4). In a selected sample the inner mineralized filamentous microbial part ( 1 and 2 measuring points on Fig. $4 \mathrm{~b}$ ) is composed of 47.8 wt. \% Si, 2.1 wt. $\% \mathrm{Fe}, 0.6$ wt. \% Al, 0.2 wt. \% Mg, 0.5 wt. \% K, 0.2 wt. \% Ca and 1.6 wt. $\% \mathrm{C}$ on average (selected elements). The content of the supposed mineralized extracellular polymeric substance around the filamentous forms (3, 4 points on Fig. 4b) is 37.9 wt. \% Si, 8.1 wt. \% Fe, 0.8 wt. \% Al, 2.6 wt. \% K, 0.4 wt. \% Ca, 0.7 wt. \% $\mathrm{Mg}, 0.1 \mathrm{wt} . \% \mathrm{Na}$ and $1.5 \mathrm{wt}$ \% $\mathrm{C}$. The silica matrix is composed of $45.7 \mathrm{wt} . \% \mathrm{Si}$, 0.3 wt. \% $\mathrm{Al}$ and 2.4 wt. \% C (5, 6 points on Fig. 4b).
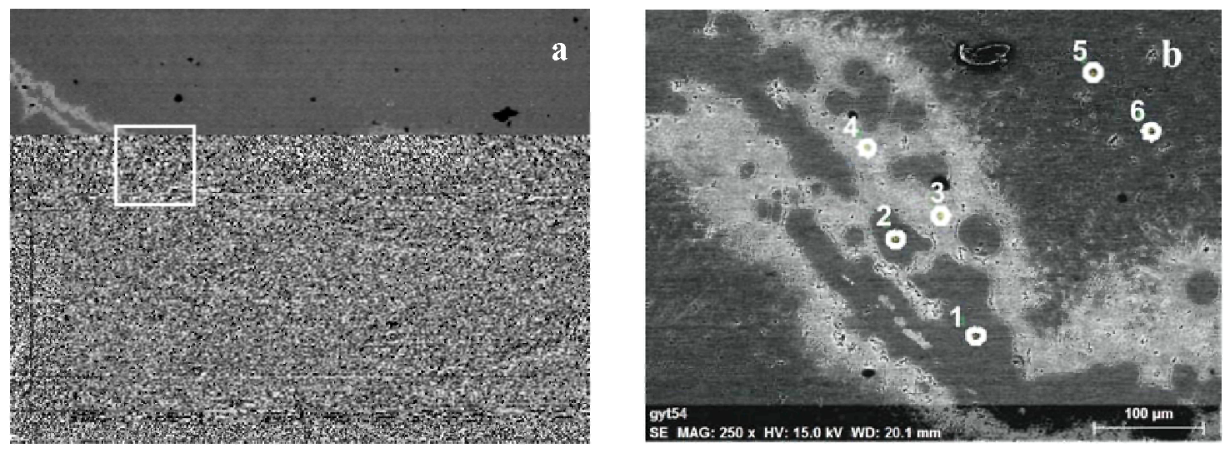

FIGURE 4. BEI of mineralized filamentous microbial forms in silica matrix (a). Higher magnification of the marked area on (a) with the EDS measuring points. 


\section{Cathodoluminescence Features}

Deep purple, dull red cathodoluminescence of the microbial textures were often observed in the thin sections by cold cathode method (Fig. 5). According to electron microprobe measurements these phases are $\mathrm{Fe}$ and $\mathrm{Si}$ rich.

Spectroscopic characterisation of the cathodoluminescence of biomineralization products and silica matrix showed variable features (Fig. 6). The silica matrix shows a bright yellow CL (Fig. 6a, b). Such CL was reported up to now exclusively from hydrothermal quartz, agates and silicified wood. The spectra show a strong CL emission band with a maximum at ca. $580 \mathrm{~nm}$. The internal structures of the silica matrix are agate-like and the banding is visible due to variations in the CL intensity, i.e. variations in the intensity of the $580 \mathrm{~nm}$ emission. This CL emission was observed in quartz samples with high contents of lattice defects (especially high concentration of oxygen vacancies, i.e. E'1 centres), these defects may be responsible for the yellow $\mathrm{CL}$ emission band at $580 \mathrm{~nm}[2,3]$. The close relationship between this emission and high concentrations of defect centres lead to the conclusion that this luminescence can be related to processes of fast crystallization. For instance, the common occurrence of the $580 \mathrm{~nm}$ emission band in cryptocrystalline quartz can possibly be related to rapid growth probably from a non-crystalline precursor.

In iron-rich areas, the matrix shows a dull reddish luminescence (Fig. 6c, d). Probably the iron oxides itself do not luminesce at all. The CL comes from the silica matrix. The spectra of the weak CL show a dominant band at ca. $650 \mathrm{~nm}$ and sometimes a shoulder (especially in the contact with "pure" silica) of a band at ca. 580 $\mathrm{nm}$.

The $650 \mathrm{~nm}$ emission is attributed to the recombination of electrons in the nonbridging oxygen band-gap state with holes in the valence-band edge [4]. A number of different precursors of this non-bridging oxygen hole centre have been proposed such as hydrogen or sodium impurities, peroxy linkages (oxygen-rich samples), or strained silicon-oxygen bonds [5]. The bond-breaking may be enhanced by the extremely high iron contents (?).The occurrence (and CL characteristics) are relatively similar for abiogenic and biogentic silica. The difference is especially in the specific features of the iron oxides. In the case of "abiogenic" agates, the crystallization of the silica matrix to micro- or macrocrystalline quartz has caused an admixture of the iron oxides and the "precipitation" along the crystallization fronts. In the biogenic samples, iron oxides create their own textures resembling the organic origin.

In sample GYT-80, a later generation of silica was observed, which cuts the "primary" yellow luminescent silica "generation". This silica type is visible by a deep blue CL (Fig. 6e, f). The emission spectra show besides the $650 \mathrm{~nm}$ emission an additional broad band in the blue around $500 \mathrm{~nm}$. Probably this band consists of two overlapping bands at 450 and $500 \mathrm{~nm}$. Because of the fine structure the spatial resolution of the analyses was not small enough to analyze the "pure" blue band. The origin of this emission is not really clear, but similar spectra were reported for opal and moganite, respectively [3]. In sample GYT-40 it seems that there is more than one "type" of blue luminescent silica. The spectra are different and show both features of quartz and poorly and non-crystalline silica, respectively. In one of the images is visible that the blue silica seems to replace the yellow type (Fig. 6g-j). 
A fourth type of silica is only visible in transmitted light and without visible CL (Fig. 6k, 1).
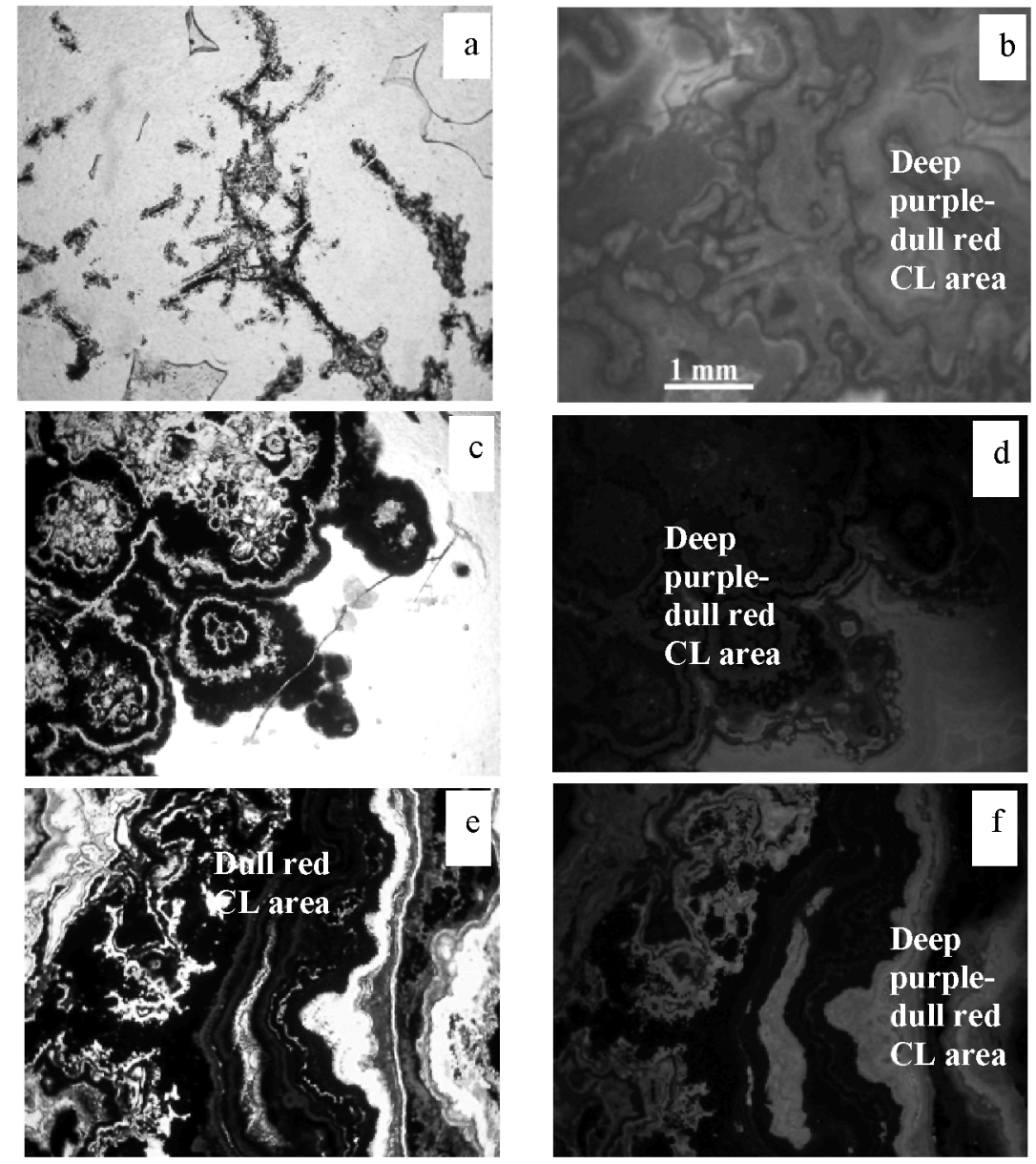

FIGURE 5. Cathodoluminescence of mineralized filamentous and other microbial forms (a) Optical microscopic photo, 1N (b) "cold cathode" cathodoluminescence of (a), (c) Optical microscopic photo, $1 \mathrm{~N}$ (d) "cold cathode" cathodoluminescence of (c), (e) Optical microscopic photo, 1N (f) "cold cathode" cathodoluminescence of (e), scale on (b) 

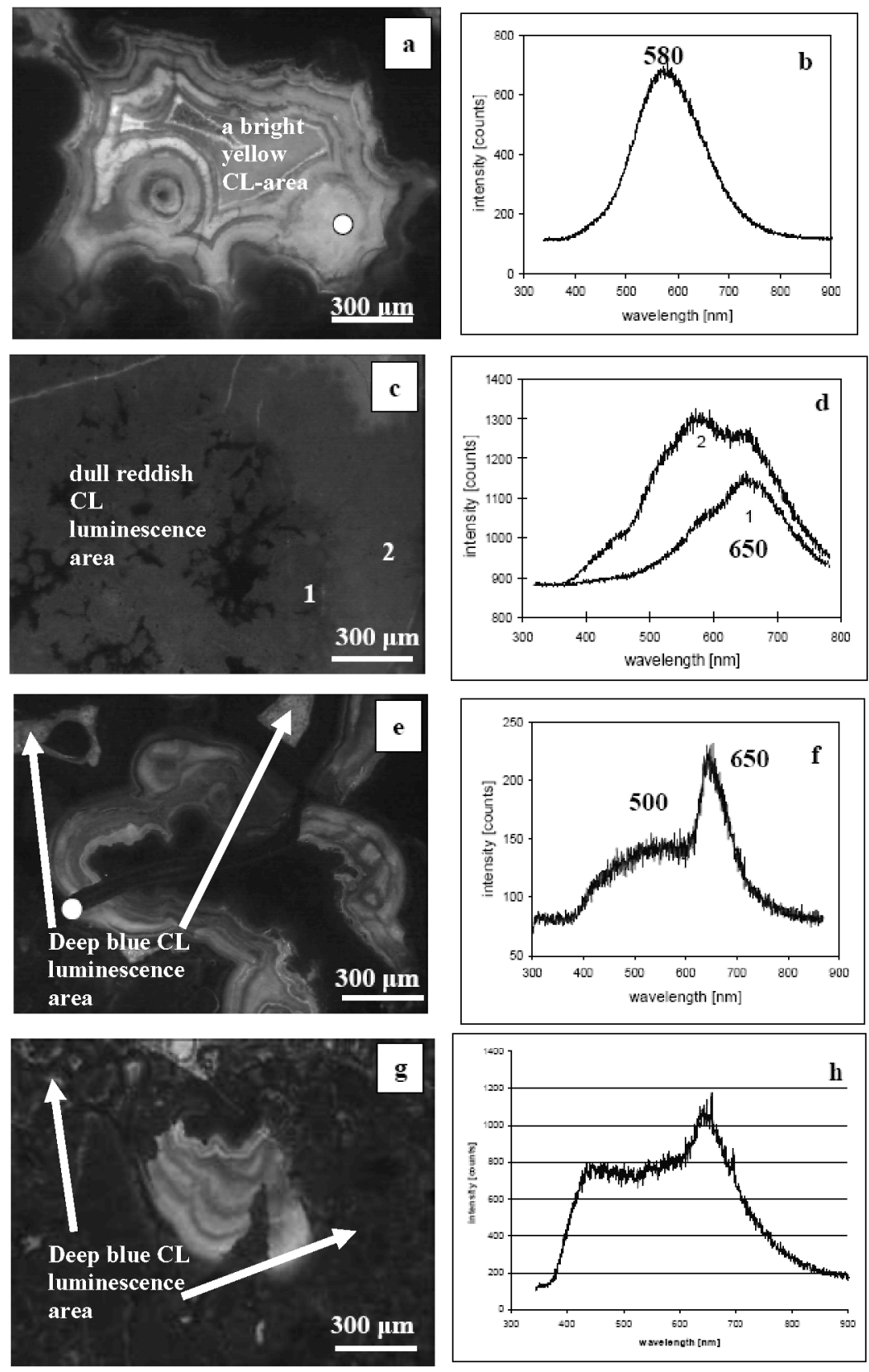

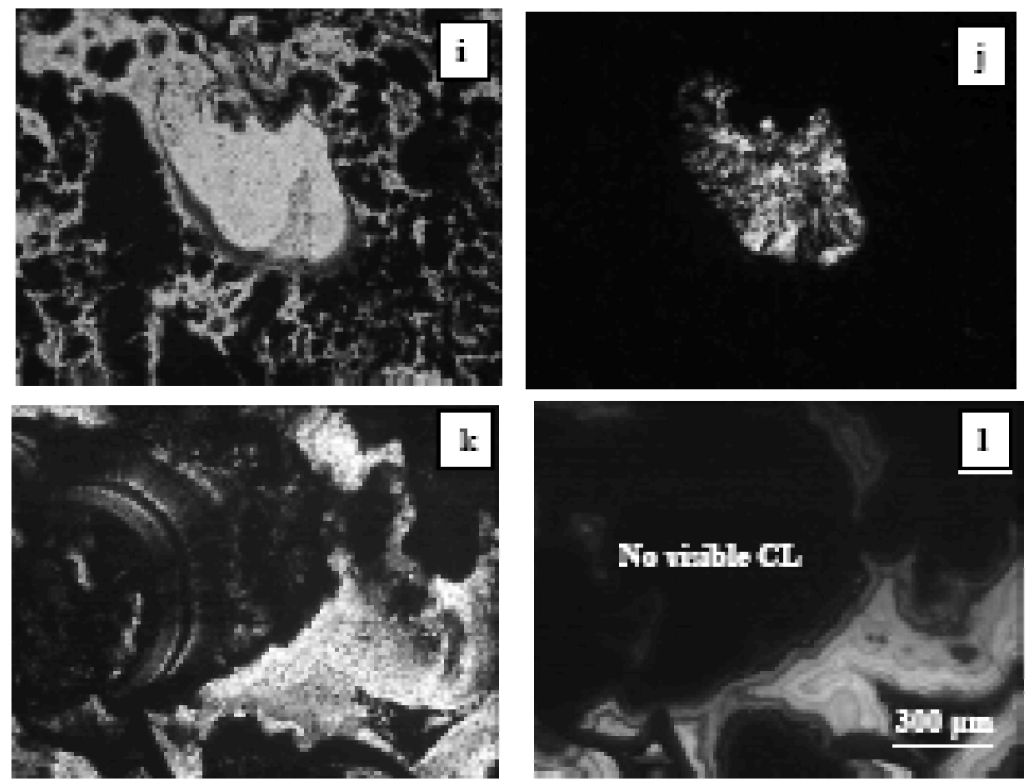

FIGURE 6. Variable cathodoluminescence features of silica matrix. (a) a bright yellow CL-area of silica matrix (b) CL spectrum of marked area on (a); (c) a dull reddish luminescence of iron-rich matrix areas; (d) CL spectrum of marked area on (c); (e, g) silica type by a deep blue CL; (f, h) CL spectrum of marked area on (e, g); (i) transmitted light photo, $1 \mathrm{~N}$ of $(\mathrm{g})$; (j) crossed $\mathrm{N}$ of (i); (k) silica is only visible in transmitted light; (1) no visible CL

Cathodoluminescence results also showed the formation of silica phases on different temperature conditions, which was probably caused by the oscillating temperature geyser and vent activity in the surrounding environment.

\section{XRD Mineralogy}

XRD mineralogy of the samples consists of opal CT, quartz, goethite, hematite, nontronite, and celadonite.

\section{Raman Spectroscopy}

Raman spectroscopy was also used to study the products of biomineralization. Characteristic peaks of calcite (at $1085 \mathrm{~cm}^{-1}$ ), hematite (at 407, 497, 608, 652 and $1320 \mathrm{~cm}^{-1}$ ), goethite (at 385,485 and $550 \mathrm{~cm}^{-1}$ ), $\alpha$-quartz (at $462 \mathrm{~cm}^{-1}$ ), moganite (at $501 \mathrm{~cm}^{-1}$ ) and different carbonaceous materials (in the $1000-1700 \mathrm{~cm}^{-1}$ region) were 
found in the spectra (Fig. 7) [6,7]. The broad bands observed in the latter spectral region indicate that this phase consists of different amorphous carbons.

In order to characterize the carbon phase in the minerals, three samples (GYT-27b, GYT-50, GYT-115; Fig. 8) were measured in more detail.

Figure 8 a shows the $800-1000 \mathrm{~cm}^{-1}$ range of the spectra measured on the GYT-27b sample. The upper curve measured in a reddish region of the surface is dominated by the peak at $1320 \mathrm{~cm}^{-1}$ related to hematite. Some broad features of small intensity can also be seen around 1090, 1500 (appearing as a shoulder) and $1890 \mathrm{~cm}^{-1}$.

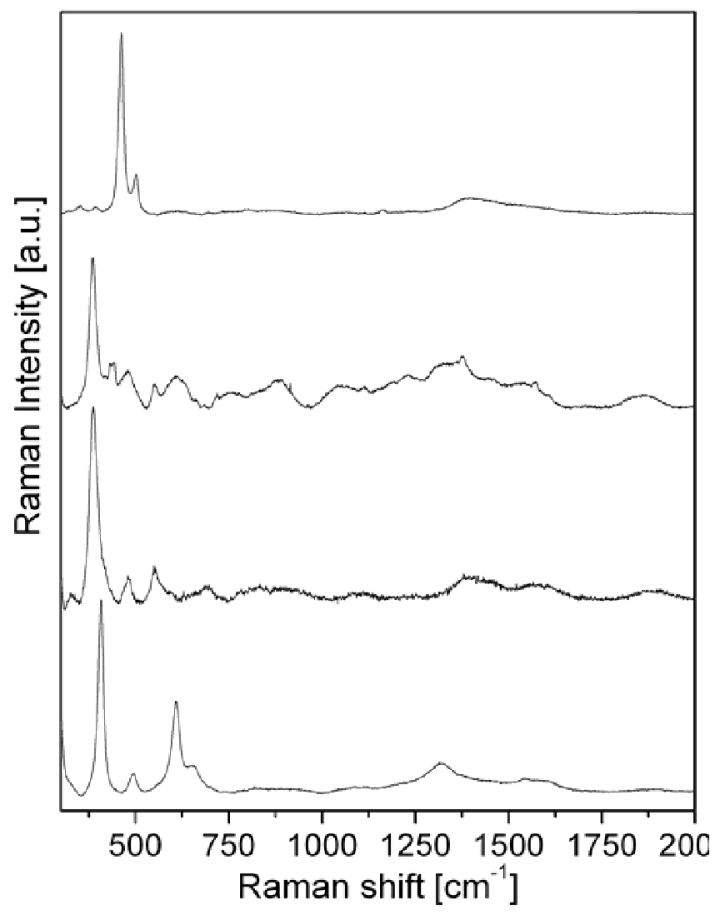

FIGURE 7. Typical Raman spectra measured in the area of mineralized filamentous microbial forms.

These features present also in the second spectrum taken near the first measurement point, but in a black part of the sample. In addition, two broad bands appear at 1360 $\mathrm{cm}^{-1}$ (as a background for the hematite peak) and $1580 \mathrm{~cm}^{-1}$, that can be identified as $\mathrm{D}$ and $\mathrm{G}$ bands of amorphous carbons [8]. According to the peak positions the $\mathrm{sp}^{2}$ hybridized carbon atoms in the amorphous phase form dominantly rings. At the same time the presence of a relatively narrow peak at $1545 \mathrm{~cm}^{-1}$ indicates some more ordered carbon material in the sample.

Signs of carbon were also observed in the spectra recorded on the GYT-50 sample (Fig. 8b). Here amorphous carbon peaks (at 1106, 1280, 1416 and $1573 \mathrm{~cm}^{-1}$ ) were detected in each measurement point. The carbon phase is of different character 
comparing to the first sample. The 1106 and $1416 \mathrm{~cm}^{-1}$ peaks indicate the presence of $\mathrm{sp}^{2}$ carbon chains in the material together with the $\mathrm{sp}^{2}$ rings. In addition spectra measured on ring-like formations of the sample surface contain two narrow bands located at 1340 and $1540 \mathrm{~cm}^{-1}$, indicating the presence of some ordered carbon phase in these formations, which support their microbial origin.

Figure 8c shows Raman spectra measured along a laminated morphological part in the third sample (GYT-115). The measurement points correspond to different laminae of the sample. The spectra are dominated by broad bands located at 1100, 1380, 1440, 1580 and $1890 \mathrm{~cm}^{-1}$, attributed to amorphous carbon [8]. Here again the characteristic peaks of $\mathrm{sp}^{2}$ rings $\left(1380\right.$ and $\left.1580 \mathrm{~cm}^{-1}\right)$ dominate the spectra. It can be seen that the character of the spectra changes when moving along the laminae. The $1580 \mathrm{~cm}^{-1}$ peak decreases when moving from the lower spectrum on the graph (corresponding to the outermost region of the laminated area) to the upper (to the innermost part), showing the increase of the $\mathrm{sp}^{2}$ ring content when moving to the outermost region of the area.

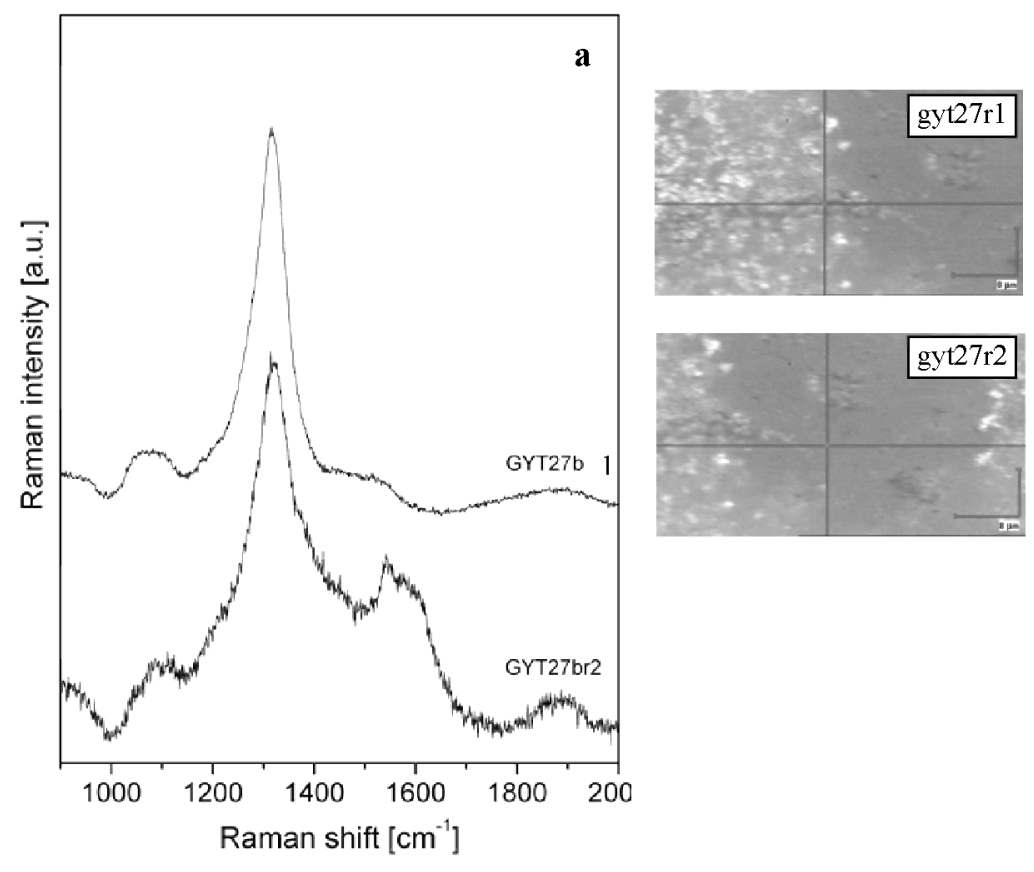



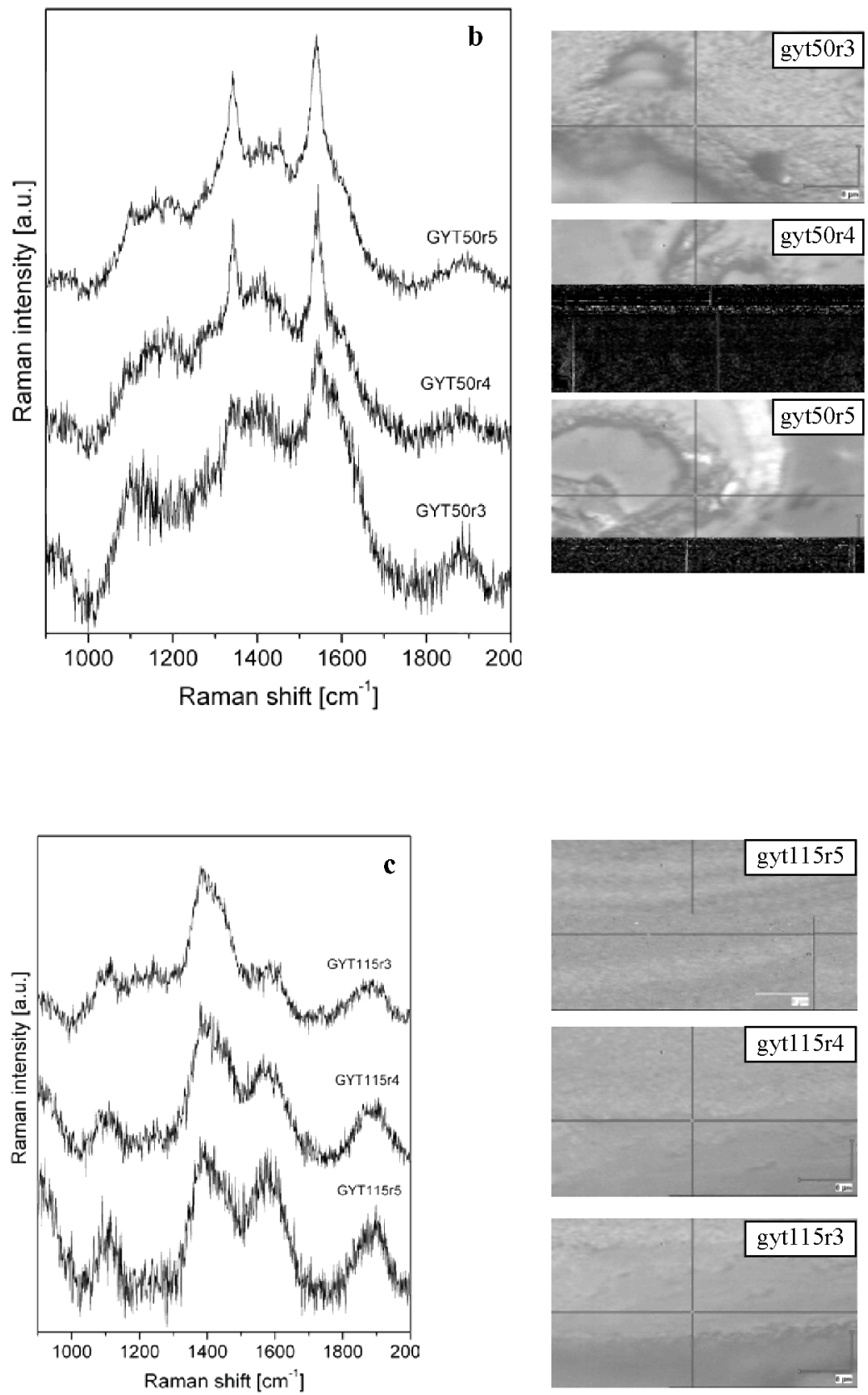

FIGURE 8. Raman spectra measured in different points of samples GYT-27b, GYT-50, GYT-115. The measurements points are indicated by the cross. 


\section{CONCLUSIONS}

Dull purple red cathodoluminescence and greenish yellow fluorescence of variable biomineralization products embedded in cryptocrystalline silica matrix were observed. Electron microprobe element measurements showed Fe-rich silica phases, with 1-3 wt. \% C, and in most cases less that $1 \mathrm{wt}$ \% $\%$ trace element contents ( $\mathrm{Al}, \mathrm{Ca}, \mathrm{Mg}, \mathrm{K}$ ) for the samples. The occurrence of amorphous carbon phases in the samples can be further evidences of microbial origin, and/or might be connected with hydrothermal contamination processes, which could serve as organic nutrients for heterotroph microbes in the system. This is also supported by the presence of moganite, which was found to form in the surrounding of organic carbonaceous phases [9]. Spectral characterisation of cathodoluminscence showed variable, four CL features of silica matrix (yellow, dull red, blue and non visible CL).

\section{ACKNOWLEDGMENTS}

The study was supported by Hungarian Science Foundation (OTKA-NKTH No. K 68992).

\section{REFERENCES}

1. T. Czakó and T. Zelenka, Advances in Space Research 1, 289-298 (1981).

2. J. Götze, M. Plötze, H. Fuch and D Habermann, Mineral Mag 63, 149-163 (1999).

3. J. Götze, M. Plötze, D. Habermann, Mineralogy and Petrology 71, 225-250 (2001).

4. G. H. Siegel and M. J. Marrone, J Non-Cryst Solids 45, 235-247 (1981).

5. M. A. Stevens Kalceff and M. R. Phillips, Phys Rev B 52, 3122-3134 (1995).

6. Kuebler et al. (2006) LPSC XXXVII, \#1907.

7. RT. Downs (2006) The RRUFF Project: an integrated study of the chemistry, crystallography, Raman and infrared spectroscopy of minerals. Program and Abstracts of the 19th General Meeting of the International Mineralogical Association in Kobe, Japan. O03-13et al., (2006) LPSC XXXVII, \#1907.

8. M. Veres, S. Tóth, M. Koós, New aspects of Raman scattering in carbon-based amorphous materials, Diamond Relat Mater 17: 1692-1696 (2008)

9. V. Kovács Kis Chert and chalcedony: Mineralogy of microcrystalline $\mathrm{SiO}_{2}$ varieties. $\mathrm{PhD}$ thesis, Budapest, Eötvös University (2000). 